\title{
PELELANGAN PROYEK KONSTRUKSI YANG DILAKUKAN MELALUI INTERNET
}

\author{
Maksum Tanubrata \\ Dosen Biasa, Jurusan Teknik Sipil, Fakultas Teknik, Universitas Kristen Maranatha \\ E-mail: maksum.tanubrata150@gmail.com
}

\begin{abstract}
ABSTRAK
Pelaksanaan lelang pengadaan dapat dilakukan secara efisien, efektif, sebanding dengan ketransparanan, adil, tidak diskriminatif dan akuntabel dengan sistem yang dapat mengakomodasi criteria di atas.Implementasi dapat terwujud dengan sistem lelang online berbasis internet. Cepatnya perkembangan teknologi informasi. E-procurement merupakan implementasi dari lelang secara elektronik yang menggunakan internet, di mana website ini sebagai media. Aplikasi ini dapat digunakan tidak hanya sebagai pengumuman dan penyimpanan dokumen, tetapi juga sebagai alat dalam proses seleksi. Berdasarkan internet, interaksi antara pembeli dan penjual dapat dioptimalkan tanpa batasan jarak dan waktu.
\end{abstract}

Kata kunci: Efisien, Efektif, Transparan, E-Procurement.

\begin{abstract}
The implementation of procurement auction can be done efficient, effective, comparable, transparent, fairness, not discriminative and accountable with the system that can accommodate the above criteria.The above implementation can be realized with the online auction system based on internet with the fast development of information technology. E-procurement is an implementation of auction electronically using internet where website is as a medium. This application can be used not only as an announcement and document storage but also as a tool in selection process. Based on internet, the interaction between buyers and vendors can be optimized without any limitation in distance and time.
\end{abstract}

Keywords: Efficient, Effective, Transparent, E-Procurement.

\section{PENDAHULUAN}

Dalam menyikapi era globalisasi pemerintah berupaya melakukan perubahan dalam peraturan proses pelelangan pekerjaan konstruksi, dimana proses pelelangan pekerjaan konstruksi diharapkan menjadi lebih efisien, efektif, terbuka, mampu bersaing, transparan, adil dan akuntabel. Seiring dengan kemajuan teknologi maka proses pelelangan yang selama ini dilaksanakan secara offline dapat berevolusi menjadi proses pelelangan yang online karena dapat mendukung prosers pelelangan yang memenuhi kriteria yang diinginkan. Untuk itu perlu dilakukan E-Procurement, yaitu pelaksanaan pelelangan konstruksi berbasis internet. Pelelangan secara online merupakan salah satu dari kemajuan teknologi informasi yang perkembangannya di Indonesia kurang begitu pesat, khususnya dalam pelelangan pekerjaan konstruksi, sehingga sangat diharapkan setelah adanya perubahan peraturan dalam proses pelelangan pekerjaan konstruksi, 
pelelangan pekerjaan konstruksi secara online mulai dapat diimplementasikan dan diaplikasikan secara lebih luas di masa mendatang.

Dalam tulisan ini, pelelangan proyek konstruksi secara online akan dibahas. EProcurement yang merupakan aplikasi pelaksanaan pelelangan berbasis internet merupakan pokok bahasan dalam tulisan ini. Alur proses e-procurement di Departemen Pemukiman Prasarana Wilayah diambil sebagai contoh studi kasus pelelangan proyek konstruksi.

\section{E-PROCUREMENT}

E-Procurement merupakan aplikasi dari pelaksanaan pelelangan secara elektronik berbasis internet. Aplikasi ini dapat berfungsi untuk media pengumuman, tempat penyimpanan dokumen sekaligus sebagai alat bantu dalam proses seleksi. Sehingga interaksi antara buyers dan vendors dapat dilakukan secara optimal, tanpa ada batasan jarak dan waktu. Penyelenggaraan aplikasi e-procurement memerlukan waktu serta proses bertahap, karena adanya perubahan kebiasaan kerja yang fundamental serta kesiapan seluruh komponen sistem yang terkait. Oleh karena itu, urutan logis dari penerapan e-procurement, dimulai dari aktivitas yang dampak efisiensinya paling besar, namun mudah pelaksanaannya dan dibagi dalam beberapa tingkatan sebagai berikut:

\section{Tingkat Persiapan}

a. Pembuatan situs dengan aplikasi dasar e-procurement

b. Pendidikan dan pelatihan sumber daya manusia menuju penerapan e-procurement

c. Sosialisasi keberadaan aplikasi e-procurement, baik untuk publik maupun penggunaan internal

d. Penyiapan peraturan pendukung.

\section{Tingkat Pematangan}

a. Pembuatan situs informasi layanan publik interaktif, yaitu dengan menambahkan fasilitas mesin pencari (search engine), fasilitas tanya jawab dan lainnya.

b. Pembuatan hubungan dengan situs informasi lembaga lainnya (hyperlink).

\section{Tingkat Pemantapan}

a. Penyediaan fasilitas transaksi secara elektronik antara lain dengan menambahkan fasilitas penyerahan formulir, fasilitas pembayaran dan lain-lain yang menjamin konektivitas yang aman, handal, dapat diakses oleh masyarakat 
b. Penyatuan penggunaan aplikasi dan data dengan lembaga lain (interoperabilitas).

\section{INFRASTRUKTUR SITUS}

Proses penerapan e-procurement yang diperlukan adalah pembuatan situ. Dalam pembuatan situs diperlukan suatu infrastruktur sebagai sarana untuk meletakkan informasi dan layanan publik secara on-line. Infrastruktur situs merupakan gabungan perangkat keras dan lunak yang membentuk fasilitas dasar (platform) untuk kegiatan layanan publik yang dilakukan oleh suatu lembaga meliputi jaringan komputer dan jaringan telekomunikasi yang menjamin konektivitas yang aman, handal, dapat diakses oleh masyarakat dan dapat digunakan sebagai media pertukaran informasi antar lembaga.

Aspek utama yang perlu diperhatikan di dalam mengembangkan infrastruktur situs adalah:

- Arah pengembangan infrastruktur informasi elektronik secara keseluruhan

- Arah pengembangan jasa layanan publik secara keseluruhan

- Arah pengembangan jenis layanan publik serta mitra dalam pembangunan dan pengoperasiannya.

Komponen utama dari suatu infrastruktur situs yang diperlukan adalah:

1. Jalur fisik informasi yan merupakan saluran komunikasi yang menghubungkan semua pengguna, baik di satu lembaga, maupun antar lembaga, dan antar daerah. Langkah-langkah yang perlu dilakukan untuk membangun jaringan fisik informasi adalah sebagai berikut:

a. Menetapkan jenis jaringan informasi yang dibutuhkan

b. Menetapkan jaringan informasi yang perlu dibangun

c. Menetapkan spesifikasi teknis dari seluruh perangkat yang dibutuhkan, meliputi:

i. Penentuan koneksi internal dan eksternal yang akan dipergunakan

ii. Penentuan kebutuhan bandwidth sesuai dengan jenis layanan.

d. Menyusun studi kelayakan finansial dan ekonomi untuk masing-masing jenis layanan

e. Mempersiapkan rencana implementasi.

2. Aplikasi-aplikasi dasar untuk mendukung kegiatan front-office dan back-office

3. Jaringan informasi global (internet).

Jaringan komputer global (internet) adalah kumpulan jaringan komputer yang saling terhubung dan menganut konsep terbuka, sehingga informasi yang ada di dalamnya 
dapat diakses secara luas. Internet menggunakan protokol komunikasi Transfer Control Protocol/Internet Proocol (TCP/IP).

Ketersediaan internet dapat dimanfaatkan sebagai media bagi masyarakat untuk mengakses informasi publik melalui Warung Internet (Warnet) ataupun Internet Service Povider (ISP). Selain itu internet dapat dimanfaatkan pula oleh lembaga pemerintah untuk mencari informasi global secara on-line dan menyebarluaskan informasi ke masyarakat dan manca negara.

\section{ALUR PROSES E-PROCUREMENT DEPARTEMENT KIMPRASWIL}

Dalam tulisan ini, Departemen Kimpraswil dipilih sebagai studi kasus $e$ procurement pelelangan proyek konstruksi, karena baru departemen ini yang melakukannya. Tabel I menunjukkan alur proses e-procurement di Departemen Kimpraswil. Pada tersebut terlihat masih ada beberapa tahapan yang diproses secara offline oleh karena itu penulis mencoba menganalisis dan membahas kendala-kendala dan pemecahannya terhadap suatu tahapan lelang yang belum dapat diproses secara online selain itu dibahas juga mengenai penyempurnaan terhadap suatu tahapan lelang yang sudah diproses secara online agar aplikasi e-procurement ini dapat berjalan secara optimal.

Tabel 1. Alur Proses Semi E-Procurement Departemen Kimpraswil.

\begin{tabular}{|r|l|c|}
\hline No & \multicolumn{1}{|c|}{ Tahapan } & Proses \\
\hline 1 & Pemaketan & online \\
\hline 2 & Pengumuman lelang & online \\
\hline 3 & Pendaftaran lelang & online \\
\hline 4 & PQ long list & online \\
\hline 5 & PQ short list & online \\
\hline 6 & Pengambilan dokumen lelang & online \\
\hline 7 & Anwijzing & offline \\
\hline 8 & Pemasukan dokumen proposal/penawaran & offline \\
\hline 9 & Pembukaan lelang & offline \\
\hline 10 & Evaluasi & offline \\
\hline 11 & Hasil penilaian administrasi & online \\
\hline 12 & Hasil penilaian teknis & online \\
\hline 13 & Hasil penilaian harga & online \\
\hline 14 & Pengumuman penetapan pemenang & online \\
\hline 15 & Masa sanggah: sanggahan dan jawabannya & online \\
\hline 16 & Penunjukkan pemenang & online \\
\hline 17 & Penayangan proposal/penawaran bagi pemenang & online \\
\hline 18 & Informasi kontrak & online \\
\hline
\end{tabular}


Aplikasi e-procurement di Departemen Kimpraswil dapat dikatakan cukup aplicable sesuai dengan data terbaru dari Departemen Kimpraswil yang mana penayangan tahapan lelang di internet telah mencapai 908 pelelangan dari 2.679 paket yang dikontrakkan (33,89\%). Sementara itu proyek konstruksi yang dilakukan melalui $e$ procurement mencapai hampir $90 \%$ dari total pelelangan yang ada. Total rekanan yang telah memenuhi persyaratan lelang semi-e-procurement sudah mencapai sekitar 400 penyedia jasa.

\section{Pemaketan}

Sistem aplikasi e-procurement di situs Departemen Kimpraswil belum memberikan fasilitas untuk pengadaan paket pekerjaan di luar Departemen Kimpraswil. Pada pengembangannya diharapkan mampu berafiliasi dengan departemen lain agar dapat menjadi fasilitator untuk pengadaan paket pekerjaan di luar Departemen Kimpraswil.

\section{Pendaftaran Kualifikasi}

Pengisian data form tambahan prakualifikasi dilakukan dengan cara meng-upload file data prakualifikasi dalam format file word dimana sebaiknya digantikan dengan metode pengisian data melalui form digital sehingga dapat memandu pengguna/user mengisi data-data dengan lengkap dan benar. Selain itu data-data tersebut dapat langsung dikelola oleh suatu sistem aplikasi database sehingga waktu pemrosesan data relatif lebih cepat. Model formnya dapat dilihat pada Gambar 1.

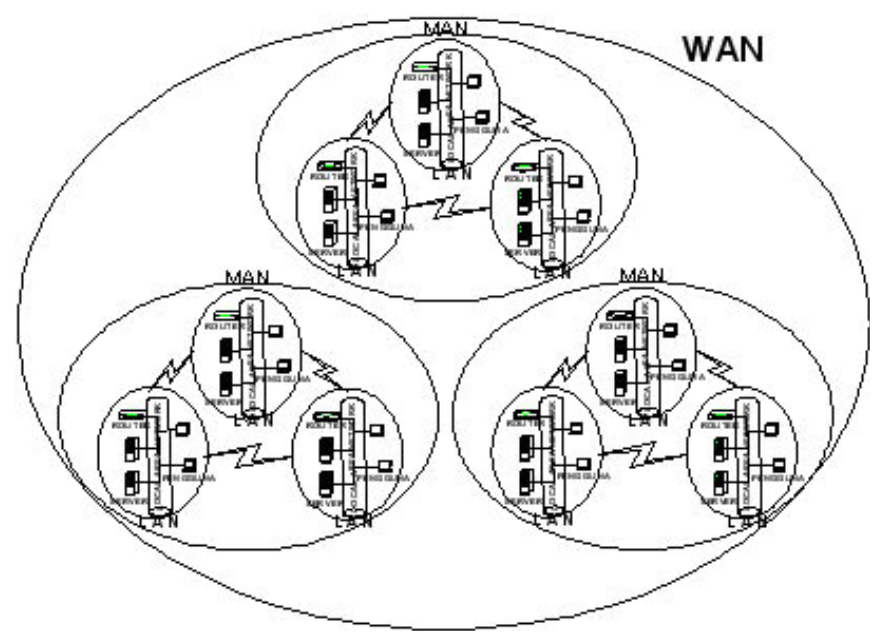

Gambar 1. Model Form Prakualifikasi. 


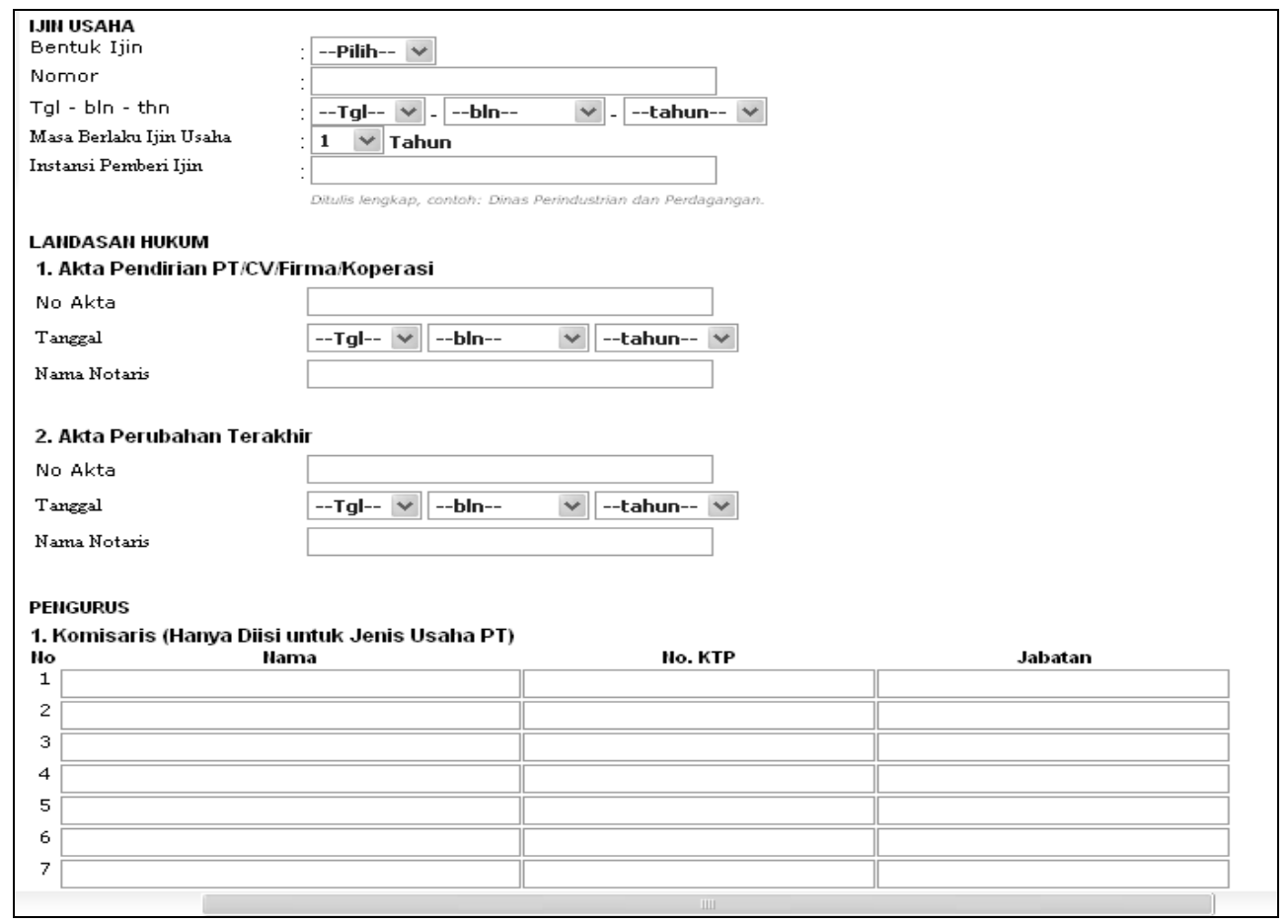

Gambar 2. Model Form Pengisian Data Prakualifikasi.

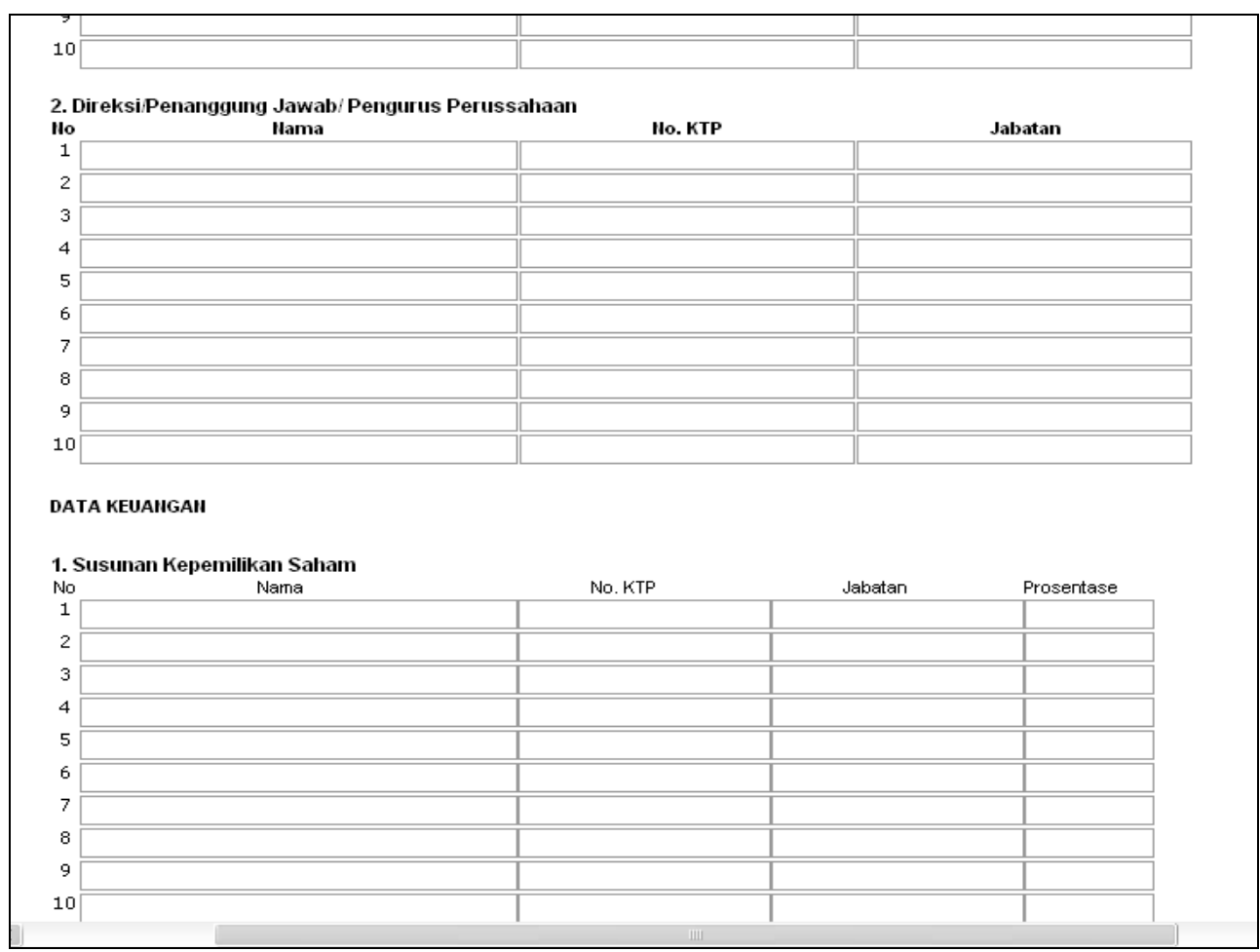

Gambar 3. Model Form Pengisian Data Prakualifikasi (Lanjutan).

Fasilitas untuk perbaikan data prakualifikasi melalui form pengisian dan upload file data prakualifikasi yang telah terkirim belum tersedia. Sementara melalui pemaketan 
terdapat fasilitas untuk memperbaiki data paket pekerjaan yang dilelangkan. Kebenaran data yang diberikan peserta kualifikasi dapat memanfaatkan fasilitas cek kebenaran data yang disediakan oleh situs LPJK (lembaga pengembangan jasa konstruksi) dan Departemen Perindustrian dan Perdagangan.

Pada situs LPJK diberikan fasilitas untuk mencek kebenaran data SDM (sumber daya manusia) dan pengalaman suatu badan usaha (lihat Gambar 4).

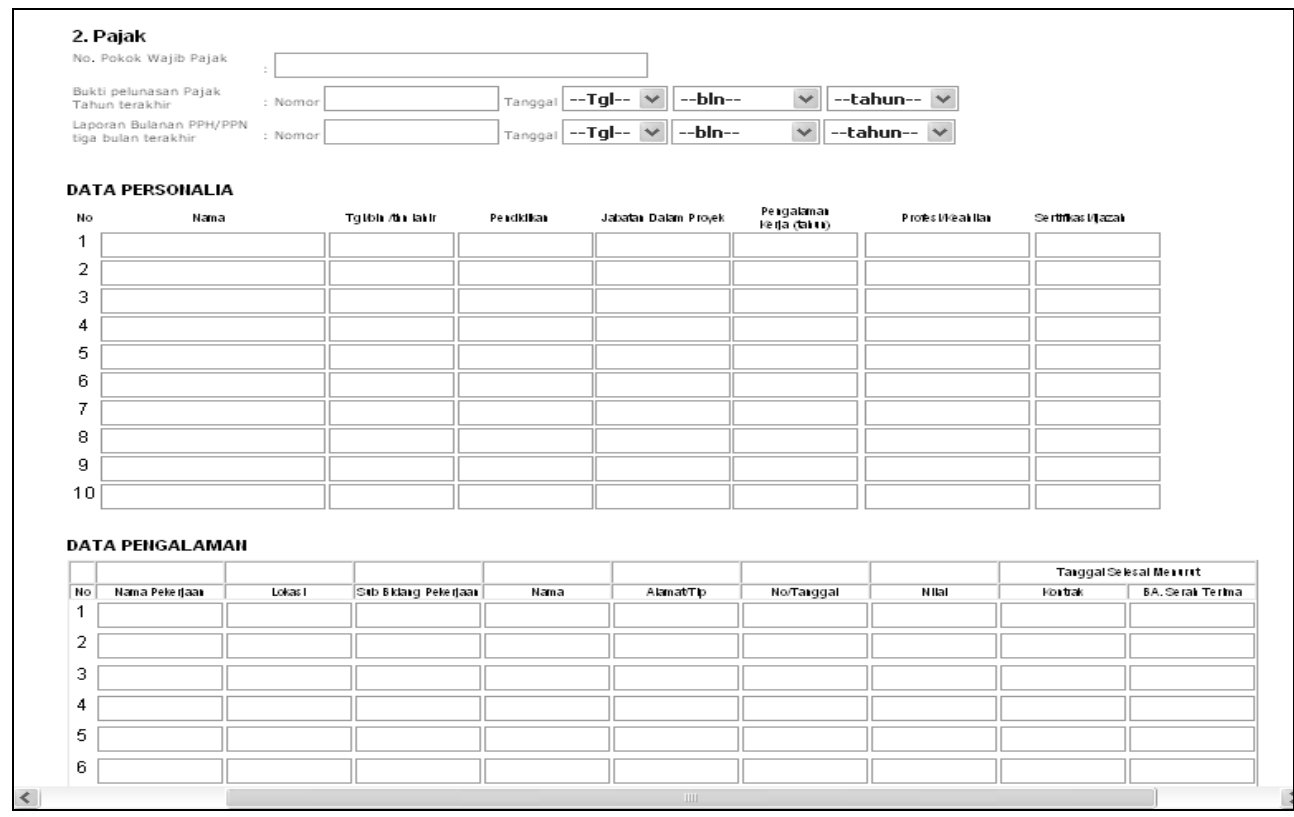

Gambar 4. Form Pengecekan Data Badan Usaha.

\section{Aanwijzing}

Aanwijzing (penjelasan pekerjaan) belum bisa dilaksanakan secara online karena peninjauan lapangan tidak bisa diproses secara online dan penjelasan dengan menggunakan fasilitas forum diskusi online dan chatting dinilai tidak efektif. Dengan demikian tahapan aanwijzing masih berjalan secara manual dan ada kontak langsung antar kontraktor sehingga masih membuka peluang KKN (korupsi, kolusi, nepotisme). Penulis berpendapat urusan KKN kembali ke moralitas masing-masing dan tak ada sistem yang seratus persen sempurna namun, setidaknya dapat meminimalkan KKN. Namun kekhawatiran akibat dari proses aanwijzing yang belum dapat dilaksanakan secara online sehingga kontak langsung antar kontraktor tak dapat dihindarkan ternyata untuk saat ini ditolong oleh Keppres no 80 Tahun 2003 dimana mewadahi hal progressive dengan diberlakukannya suatu aturan baru yang menyebutkan tidak bisa digugurkannya penawaran calon penyedia barang/ jasa yang tidak hadir pada Aanwijzing Pelelangan Proyek Konstruksi Yang Dilakukan Melalui Internet (Maksum Tanubrata) 
yang diadakan panitia pengadaan. Sehingga calon kontraktor/ supplier yang tidak ingin hadir karena takut dipaksa kolusi antar mereka atau tidak bisa hadir karena alasan teknis dan jarak tetap bisa memberikan penawaran

\section{Pemasukan Dokumen Penawaran}

Proses tersebut belum dapat dilakukan secara online sehingga otomatis untuk tahap pembukaan dan evaluasi penawaran dilaksanakan secara offline. Pemasukan dokumen penawaran dilaksanakan secara offline karena dokumen-dokumen yang diperlukan harus dilegalisasi oleh pihak lain.

Keberadaan berbagai institusi pendukung dalam pelaksanaan pengadaan barang/jasa pemerintah yang bersifat sebagai pendukung dalam penyiapan dokumen secara integral. Dalam aplikasinya dilengkapi dengan multilink system sehingga mampu menghubungkan berbagai komponen yang terkait secara inter-operability. Ilustrasi dapat dilihat pada Gambar 5.

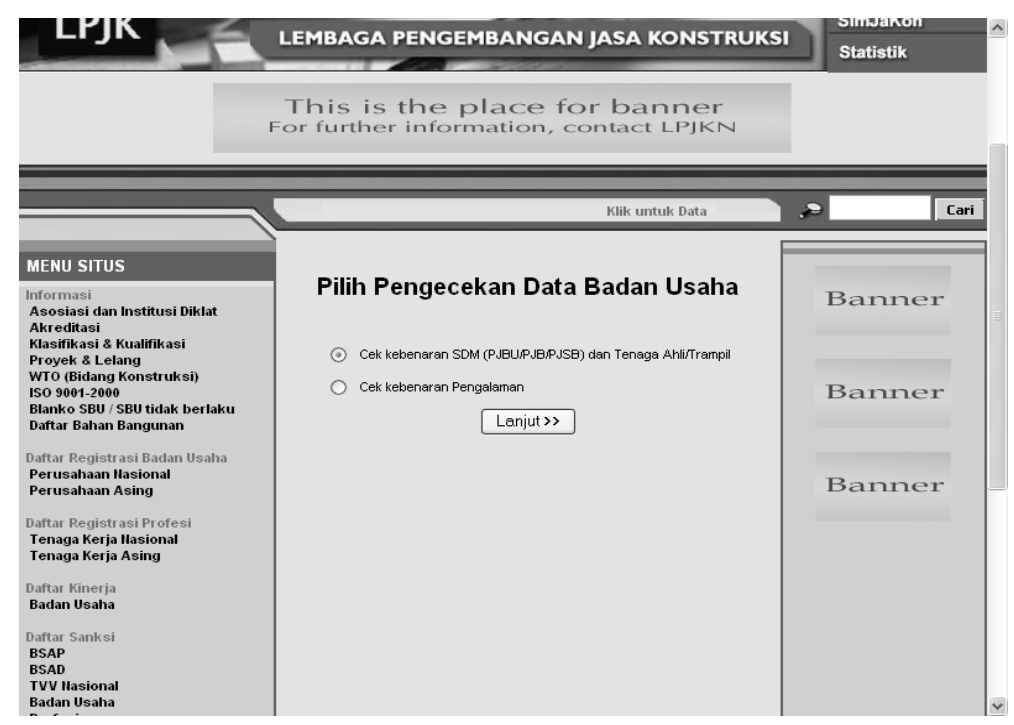

Gambar 5 Sistem Aplikasi E-procurement.

Legalisasi suatu dokumen dengan menggunakan metode database mitra pendukung lebih cepat diimplementasikan karena tidak mengalami proses standarisasi dan registrasi yang kompleks. Selain itu metode database mitra pendukung dapat mempercepat proses pengolahan data.

Pemasukan dokumen penawaran secara online sangat strategis bila beberapa proses yang memungkinkan dapat di-otomatisasi, contohnya pencatatan terhadap data waktu, tanggal penerimaan dokumen penawaran, pemblokiran dokumen penawaran 
dimana waktu pemasukannya melampaui waktu batas akhir sehingga tidak diperlukan konfirmasi untuk setiap penawaran yang diblokir kepada peserta lelang. Contoh lain dokumen penawaran pada surat penawaran untuk data yang tidak memerlukan uraian panjang seperti jangka waktu berlaku surat penawaran, jangka waktu pelaksanaan pekerjaan. Tetapi sebaiknya diisikan melalui suatu form digital untuk memudahkan dalam pengolahan data sedangkan pada daftar kuantitas dan harga satuan dapat dibuat dalam format file excel sehingga data-data dapat langsung diolah dan dievaluasi dengan menggunakan suatu tools makro microsoft excel decision tools.

Pengimplementasian fasilitas transaksi secara elektronik untuk fasilitas penyerahan formulir dan fasilitas pembayaran diperlukan suatu konsep dan sistem yang mendukung. Selain itu landasan peraturan perundang-undangan yang berhubungan dengan pemanfaatan aplikasi e-procurement sangat diperlukan, khususnya dalam pengaturan masalah keamanan dan kejahatan komputer atau kejahatan yang dilakukan dengan menggunakan internet.

\section{KESIMPULAN DAN SARAN}

\section{Kesimpulan}

1. Penerapan semi-e-procurement membuat sebagian proses tatap muka, dimulai dari tahap pengumuman, prakualifikasi, hingga pelelangan, berkurang dan digantikan internet. Pengambilan formulir secara online, download dokumen lelang berita acara pembukaan dokumen lelang, hingga sanggahan sehingga dapat meminimalkan KKN. Penerapan semi-e-procurement masih membuka peluang KKN. Sebagian proses masih berjalan manual dan ada kontak langsung

2. Aplikasi sistem e-procurement memerlukan waktu dan proses bertahap, karena perubahan kebiasaan kerja yang fundamental serta kesiapan seluruh komponen yang terkait.

3. Apabila e-procurement sudah diterapkan secara penuh, maka:

a. Baik panitia maupun pengguna dapat melakukan interaksi terkait dengan tanggungjawab masing-masing secara lebih bebas, tanpa terbatasi oleh jarak dan waktu. Sehingga proses secara keseluruhan dapat diselesaikan dengan cepat.

b. Berbagai persyaratan dokumen, sarana dan prasarana pelelangan, honorarium staf, konsumsi, kurir dan hal-hal lain yang membutuhkan biaya dapat diminimalisir. Demikian pula untuk penyedia, berbagai aktifitas terkait dengan 
penyiapan persyaratan pelelangan yang akan diikuti juga dapat dilakukan dengan lebih hemat.

\section{Saran}

Pelaksanaan e-procurement akan optimal jika dilengkapi dengan :

1. Sistem aplikasi yang memiliki kemampuan interoperabilitas sehingga dapat menghubungkan berbagai komponen yang terkait dengan proses e-procurement

2. Keamanan sistem aplikasi e-procurement diantaranya keamanan jaringan yang menjamin konektivitas yang aman, handal dan cepat termasuk tingkat proteksi keamanan dokumen elektronik yang memenuhi aspek legal dan bobot bukti.

3. Landasan peraturan yang mendukung implementasi pengadaan barang/jasa milik pemerintah secara elektronik.

\section{DAFTAR PUSTAKA}

1. Ervianto Wulfram (2002), "Manajemen Proyek Konstruksi”, ANDI, Yogyakarta

2. Tim Penyusun Keppres (2003), "Pedoman Pelaksanaan Pengadaan Barang/Jasa Pemerintah”, KEPPRES No. 80 Tahun 2003, CV. Tamika Utama, Jakarta.

3. Tim Penulis GIPI, (2004), Rating Web, http://gipi.go.id

4. Tim Penulis Quantum eCommerce College (2001), Diktat Kuliah Pemrograman Internet Dasar, Quantum eCommerce College, Bandung

5. Tim Penulis Quantum eCommerce College (2002), Diktat Kuliah Teknologi Server dan Jaringan, Quantum eCommerce College, Bandung.

6. Tim Penulis Quantum eCommerce College (2002), Diktat Kuliah Web Design dan Tata Letak Web, Quantum eCommerce College, Bandung.

7. Tim Telematika Indonesia (2003), "Infrastruktur Informasi Elektronik", http://www.kominfo.go.id

8. Tim Telematika Indonesia (2003), “Manajemen Dokumen Elektronik”, http://www.kominfo.go.id

9. Tim Telematika Indonesia (2003), “Pemerintah RI Dengan Seluruh Jajarannya Dapat Melaksanakan Pengadaan Barang/Jasa Secara Elektronik (EProcurement)", http://www.kominfo.go.id

10. Tim Telematika Indonesia (2003), “Sistem Keamanan Jaringan”, http://www.kominfo.go.id 